\title{
An Alternative to Accurate Pyrometry in Distinguishing Con- current Vaporization Reactions. Postulated Results Using the Vaporization of Gold in Analyzing the Vaporization of Beryllium Oxide in Water Vapor*
}

\author{
Thomas B. Douglas \\ Institute for Materials Research, National Bureau of Standards, Washington, D.C. 20234
}

(April 27, 1972)

\begin{abstract}
For the transpiration determination of vaporization properties whose interconsistency is critical, the simultaneous vaporization of a reference substance such as uncontaminated gold is suggested as an alternative to accurate pyrometry. Calculations suggest that gold would be superior to all but the most accurate pyrometry in the temperature range 1700 to $2300 \mathrm{~K}$. An application to seeking unreported gaseous hydrates of beryllia is illustrated by calculations based on estimated thermodynamic parameters.
\end{abstract}

Key words: Beryllia hydrates (gases); contaminants; gold; pyrometry; reference vaporization; temperature consistency; thermodynamic parameters (estimated).

\section{Introduction}

Many a substance vaporizes to produce by independent equilibria two (or more) gaseous species, and it is commonly of practical as well as scientific interest to distinguish and measure separately the different equilibria involved. In some cases this can be accomplished by some spectroscopic technique which discriminates between the two species. In other cases that expedient is not practical, but one may be able to apply some technique (such as transpiration) to measure accurately the total of the two species (or the total of some component which they both contain).

If the two species are formed by nearly the same molar heats, their proportion will change little with temperature, and such a gross technique as transpiration cannot distinguish them. However, very commonly these heats differ widely; in such a case the primary species often greatly predominates in one temperature range (say, absolute temperatures $T_{1}$ to $T_{2}$ ), with the proportion of the secondary species becoming much greater at higher temperatures (say, typically at $T_{3}$ ). Consider first the range $T_{1}$ to $T_{2}$. Insofar as the secondary species is negligible and the primary species approximates an ideal gas produced with a heat independent of temperature (or if deviations from these conditions can be corrected for), one gets a linear varia-

\footnotetext{
*This work was sponsored by the U.S. Air Force Office of Scientific Research under Con
} tract Nos. AFOSR-ISSA-69-001 and 71-0003. tion of $\log K^{\prime}$ with $1 / T$, where $K^{\prime}$ is the equilibrium constant for the primary vaporization reaction. Then one may extrapolate $\log K^{\prime}$ linearly to $1 / T_{3}$ and attribute the excess of the measured extent of vaporization to the contribution at $T_{3}$ of $K^{\prime \prime}$, corresponding to formation of the secondary species. (And, if data are obtained also at an additional temperature where the secondary species is an important one, then one can, at least in principle, determine an averaged value for the heat of its production.)

The foregoing procedure presupposes sufficiently accurate temperature measurement to establish the deviation from linearity of the measured (overall) $\log K$ versus $1 / T$. In the range of high temperatures which are measured by pyrometer, this instrument in principle measures the thermodynamic temperatures required, but in practice involves systematic errors rendering the $\log K$ versus $-1 / T$ curvature uncertain if the contribution of the secondary vapor species is quite small even at $T_{3}$. It is the purpose of this article to investigate the feasibility of relying, instead, on the simultaneous vaporization of a second, reference substance to reduce the effects of temperature errors.

That this alternative is capable of being made quite successful is most clearly suggested by a simple idealized situation which is approximated by many real systems. Suppose that the substance being investigated and the reference substance each vaporize 
to form a primary gas species with equilibrium constants $K_{i}^{\prime}$ and $k_{i}^{\prime}$, respectively, at temperature $T_{i}$. Suppose also that the heats of these two vaporization reactions are independent of temperature. Then we can write

$$
\log K_{i}^{\prime}=-A / T_{i}+B
$$

and

$$
\log k_{i}^{\prime}=-a / T_{i}+b
$$

where $A, B, a$, and $b$ are constants. Let eqs (1) and (2) each be applied at temperatures $T_{1}, T_{2}$, and $T_{3}$. Then the six equations can be used to eliminate the seven unknowns $A, B, a, b, T_{1}, T_{2}$, and $T_{3}$, giving

$\log \left(K_{3}^{\prime} / K_{2}^{\prime}\right) / \log \left(K_{2}^{\prime} / K_{1}^{\prime}\right)=\log \left(k_{3}^{\prime} / k_{2}^{\prime}\right) / \log \left(k_{2}^{\prime} / k_{1}^{\prime}\right)$.

Now suppose that $k_{1}, k_{2}, k_{3}, K_{1}$, and $K_{2}$ represent virtually all the respective vapors produced at the designated temperatures, and also that they are known with sufficient accuracy from the measured masses evaporating. Then the magnitude by which the similarly determined value of $K_{3}$ exceeds $K_{3}$ as given by eq (3) is a measure of the secondary species in equilibrium with the nonreference substance at $T_{3}$. In this, one need make no use of known properties of the reference substance such as vapor pressuresdata which themselves may be subject to systematic errors of pyrometry. In addition, no temperature measurements are required (except approximate ones to complete the description of the effects observed).

Unfortunately, it is difficult to find a reference substance of suitable high-temperature volatility which fulfills the above ideal criterion: usually one or more secondary species are formed which must be properly accounted for, and also invariably all heats of vaporization vary appreciably with temperature. Because the treatment is then more complicated and its success hinges on the accuracies of several input data which will vary widely from case to case, further elaboration of the treatment will be presented here only in the form of a specific example. The example considered is the use of gold as a reference substance in a suggested transpiration investigation of the vaporization of beryllium oxide into water vapor, and under conditions where at least two "beryllia hydrate" gas species can be expected to be formed. (The necessary large excess of water vapor effectively precludes alternative spectroscopic techniques.) No experimental data of the type proposed are available as a test (in fact, the molecule $(\mathrm{BeO})_{2} \cdot \mathrm{H}_{2} \mathrm{O}$ has never been reported), but detailed calculations based on experimental and estimated parameter values and their uncertainties afford enlightening quantitative comparisons between gold vaporization and pyrometry as alternative means of establishing the necessary temperature relations.

\section{The Proposed Procedure Exemplified}

\subsection{Identification of Parameters}

For the simultaneous evaporation of beryllium oxide into water vapor and of gold into an inert medium, four vaporization reactions are considered, these being

$$
N \mathrm{BeO}(\mathrm{c})+\mathrm{H}_{2} \mathrm{O}(\mathrm{g})=(\mathrm{BeO})_{N} \cdot \mathrm{H}_{2} \mathrm{O}(\mathrm{g})
$$

and

$$
n \mathrm{Au}(l)=\mathrm{Au}_{n}(\mathrm{~g})
$$

with $N$ and $n$ each having values of 1 and 2 . It is possible to write a chain valence structure for $(\mathrm{BeO})_{N} \cdot \mathrm{H}_{2} \mathrm{O}$ for any integer value of $N$. However, the available evidence indicates that in the temperature range considered $(<2500 \mathrm{~K})$, product species with higher values of $N$ and $n$ are probably present in negligible abundance. Each gas is assumed to be ideal. We shall write for the equilibrium constant $K_{P}^{\prime}$ of reaction (4), $N=1$, at absolute temperature $T$ the usual third-law equation

$$
\ln K_{p}^{\prime}=-\frac{\Delta H^{\prime}}{R T}+\frac{\Delta S^{\prime \prime}}{R},
$$

and for $N=2$ the same equation except with double primes replacing the single primes. $\left(\Delta C_{P}^{\prime}\right.$ and $\Delta C_{P}^{\prime \prime}$ will be used to represent the variation with temperature of $\Delta H^{\prime}$ and $\Delta H^{\prime \prime}$, respectively.) The analogous equation for reaction (5), $n=1$, will be written

$$
\ln k_{p}^{\prime}=-\frac{\Delta h^{\prime}}{R T}+\frac{\Delta s^{\circ{ }^{\prime}}}{R},
$$

using double primes for $n=2$.

The calculations to be made will be for the occurrence in a transpiration experiment of reactions (4) and (5) simultaneously at each of three temperatures $T_{1}=1700 \mathrm{~K}, T_{2}=2000 \mathrm{~K}$, and $T_{3}=2300 \mathrm{~K}$, the equilibrium constants at any one of these temperatures $T_{i}$ being designated $K_{i}^{\prime}, K_{i}^{\prime \prime}, k_{i}^{\prime}$, and $k_{i}^{\prime \prime}$. In such an experiment the flowing gases are cooled downstream, whereupon reactions (4) and (5) are reversed, and the total $\mathrm{BeO}$ and $\mathrm{Au}$ condensed are used to calculate values $K_{i}$ and $k_{i}$ as if $N=1$ only and $n=1$ only. (The $\mathrm{H}_{2} \mathrm{O}(\mathrm{g})$ would be present in great excess for reaction (4).) Since the transpiration measures only the total number of monomer units in the vapor (equivalent to $K_{i}$ or $k_{i}$ ), we then have

$$
K_{i}=K_{i}^{\prime}+2 K_{i}^{\prime \prime}
$$

and

$$
k_{i}=k_{i}^{\prime}+2 k_{i}^{\prime \prime}
$$


Since $n$ and $T$ may both vary in eq (7), while only $T$ may vary in eq (9), eqs (7) and (9) lead to six and three independent equations, respectively. The nine equations represented by eqs (7) and (9) make it possible to eliminate the six $k_{i}^{\prime}$ and $k_{i}^{\prime \prime}$ values and determine the three temperatures $T_{i}$. Then the nine equations represented by eqs (6) and (8) may be used to eliminate the values of $\Delta H^{\prime}$ and $\Delta S^{\circ \prime}$ at some one temperature, as well as the six $K_{i}^{\prime}$ and $K_{i}^{\prime \prime}$ values, determining $\Delta H^{\prime \prime}$ for some one temperature if a value of $\Delta S^{\prime \prime}$ is assumed. (Measurement also at one or more additional temperatures could help improve the evaluation of these properties.)

\subsection{Selection of Parameter Values}

For the calculations of section 2.3 the parameter values for reactions (4) ${ }^{\circ}(\mathrm{eq}$ (6)) were selected as follows. At $1600 \mathrm{~K}$ the hydrate with $N=2$ is apparently negligible, and averaging the experimental results of three sets of investigators $[1,2,3]^{1}$ gave as mean second-law values $\Delta H_{1600}^{\prime}=41.4 \mathrm{kcal}$, and $\log _{10} K_{1600}^{\prime}$ $=-3.926$, with which the estimated parameter values are consistent. The two "beryllia hydrate" molecules were assumed to be linear ${ }^{2}$ chains $\mathrm{HOBeOH}$ and $\mathrm{HOBeOBeOH}$, with $\mathrm{O}-\mathrm{H}$ and $\mathrm{Be}-\mathrm{O}$ distances of 0.96 and $1.40 \AA$ respectively. The vibrational fundamentals (in $\mathrm{cm}^{-1}$ and with degeneracies in parantheses) were estimated on the basis of analogs to be $3500(2)$, $1350(2), 574(4)$, and $350(2)$ for $\mathrm{BeO} \cdot \mathrm{H}_{2} \mathrm{O}$; and $3500(2)$, $1125(4), 574(4), 350(4)$, and $140(2)$ for $(\mathrm{BeO})_{2} \cdot \mathrm{H}_{2} \mathrm{O}^{3}$ Using the known heat capacities of $\mathrm{BeO}(\mathrm{c})$ and $\mathrm{H}_{2} \mathrm{O}(\mathrm{g})$ [4], $\Delta C_{P}^{\prime}=3.6-0.0023 \quad T$ cal $\mathrm{mol}^{-1} \mathrm{~K}^{-1}$ was derived for reaction (4) (1700-2300 K); for simplicity, $\Delta C_{P}^{\prime \prime}=0$ was assumed. If the experimental enthalpies of dissociation at $298 \mathrm{~K}$ of several molecules are assumed to be composed of apparent bond energies with $\mathrm{O}-\mathrm{H}$ the same as in $\mathrm{H}_{2} \mathrm{O}$ and $\mathrm{Be}-\mathrm{F}$ the same as in $\mathrm{BeF}_{2}$, then the $\mathrm{Be}-\mathrm{O}$ bond energy is nearly constant in the unstrained cases. For $(\mathrm{BeO})_{2-6}$, $\mathrm{Be}_{2} \mathrm{OF}_{2}$, and $\mathrm{Be}(\mathrm{OH})_{2}$, it is respectively $94,111,116$, $120,122,122$, and $119 \mathrm{kcal} \mathrm{mol}^{-1}$ [4], and was somewhat arbitarily assumed to be $12 \mathrm{l}$ in $(\mathrm{BeO})_{2} \cdot \mathrm{H}_{2} \mathrm{O}$. The last value corresponds to a $(\mathrm{BeO})_{2} \mathrm{H}_{2} \mathrm{O}: \mathrm{BeO} \cdot \mathrm{H}_{2} \mathrm{O}$ mole ratio for reaction (4) varying from about 0.005 at $1700 \mathrm{~K}$ to about 0.07 at $2300 \mathrm{~K}$.

The parameter values selected as suitably representing the presently available thermodynamic data for reactions (5) are those given in table 1 , column 5 (sec. 2.3). These values were taken from several sources $[5,6,7,8,9]$. It should be noted that the availability of heat-capacity data for solid and liquid gold and spectroscopic data for the gas species ( $\mathrm{Au}$ and $\mathrm{Au}_{2}$ ) allows a third-law treatment which still requires an accurate experimental vapor pressure of gold but at a single temperature. ( $1700 \mathrm{~K}$ is representative of the best vapor-pressure data for gold.) Hence the

\footnotetext{
Figures in brackets indicate literature references at the end of this paper.

${ }^{2}$ It is not unlikely that they are bent, but their shape has no significant effect on their

estimated thermodynamic properties.
3 These modes may be described as $\mathrm{OH}$ stretching, $\mathrm{BeO}$ stretching, $\mathrm{HOBe}$ bending, $\mathrm{OBeO}$ bending, and $(N=2$ only) $\mathrm{BeOBe}$ bending, respectively. The $\mathrm{BeO}$ stretching frequencies were estimated by S. Abramowitz.
}

parameters for reactions (5) are sensitive to only this one temperature error-and even this to a reduced extent for the present purposes, as illustrated in the next section.

\subsection{Calculated Propagation of Systematic Errors}

Using the adopted parameter values and values of $k_{1}, k_{2}$, and $k_{3}$ corresponding to exactly 1700,2000 , and $2300 \mathrm{~K}$ for $T_{1}, T_{2}$, and $T_{3}$ respectively, the procedure of section 2.1 gave $\Delta H^{\prime \prime}=73.40 \mathrm{kcal}$. This computer calculation (involving linearization and iteration) was repeated 14 times except each time varying one parameter in order to determine the sensitivity of the calculated results to error in that parameter. The details are given in table 1 . In order to reduce these calculated errors to the basis of a single temperature error, the error in $T_{3}$ was then calculated on the basis of measuring $T_{1}$ and $T_{2}$ correctly (column 11), and this was done by multiplying the entry in column 10 by the factor $0.26 / 0.11$ from case 10 , where an error in $T_{3}$ only was assumed. This affords an interesting comparison particularly for case No. 2. In this case a postulated error of $0.3 \mathrm{kcal}$ in $h$ is seen to lead to errors of 6 to $9 \mathrm{~K}$ in $T_{1}, T_{2}$, and $T_{3}$. The equivalent error in column 11 is not zero (as it would be were the simple idealized situation described in the Introduction true: only one vapor species, and $\Delta C_{p}=0$ ), but it is only about one-tenth as great as the individual errors in $T_{1}, T_{2}$, and $T_{3}$.

An attempt was made to select for the postulated errors in table 1 (column 6) conservative estimates of realistic uncertainties in the 14 parameter values, assuming careful experimental work. ${ }^{4}$ Then one can combine the errors in column 11 to assess the overall thermometric uncertainty, or the errors in column 10 to assess the uncertainty in the value of the desired quantity $\Delta H^{\prime \prime}$. It should be borne in mind that the accuracy of approximately 2 percent in $\Delta H^{\prime \prime}$ indicated by table 1 would hold only for the postulated equilibrium abundances of $(\mathrm{BeO})_{2} \cdot \mathrm{H}_{2} \mathrm{O}$ relative to $\mathrm{BeO} \cdot \mathrm{H}_{2} \mathrm{O}$. There is presently no certainty that these abundances are not actually much smaller or much greater, in which case experimental data of this type would obviously give greater or smaller uncertainties, respectively, in the thermodynamic properties of $(\mathrm{BeO})_{2} \cdot \mathrm{H}_{2} \mathrm{O}$.

The statistical combination of the errors in table 1 , column 11 , for cases $2-10$ is $1.5 \mathrm{~K}$ (square root of the summed squares). This figure is independent of the foregoing ambiguity arising from the $\mathrm{BeO}-\mathrm{H}_{2} \mathrm{O}$ system, and may be compared with the corresponding temperature uncertainty if $T_{1}, T_{2}$, and $T_{3}$ were measured by a pyrometer instead. For careful determination of temperatures below and above $2000 \mathrm{~K}$, "maximum error" uncertainties using an optical pyrometer are sometimes stated as $(T / 1000)^{2}$, and "standard error" uncertainties using a photoelectric pyrometer have

\footnotetext{
${ }^{4}$ The existing data may have uncertainties exceeding the entries for cases 3 and 4 but accurate calorimetric data could easily reduce these uncertainties to the levels tabulated. The postulated errors for cases 8-13 were selected after consideration of the following facts: From 1700 to $2300 \mathrm{~K}$ the amount of $\mathrm{BeO}$ evaporating would vary from 0.05 to $0.9 \mathrm{mg}$ per liter of $\mathrm{H} O(g)$ at $\mathrm{l}$ atm pressure; the corresponding amount of gold evaporating would vary from 0.03 to $11 \mathrm{mg}$ per liter of nonreacting gas.
} 
TABLE 1. Effect, on calculated results, of estimated error in each input datum

\begin{tabular}{|c|c|c|c|c|c|c|c|c|c|c|}
\hline 1 & 2 & 3 & 4 & 5 & 6 & 7 & 8 & 9 & 10 & 11 \\
\hline \multirow{2}{*}{$\begin{array}{l}\text { Case } \\
\text { No. }\end{array}$} & \multicolumn{2}{|r|}{ Erroneous parameter } & \multicolumn{3}{|c|}{ Input data } & \multicolumn{5}{|c|}{ Calculated results } \\
\hline & Symbol & Definition & $\begin{array}{l}\text { Units } \\
\text { used }\end{array}$ & $\begin{array}{c}\text { Value } \\
\text { assumed }^{a}\end{array}$ & $\begin{array}{l}\text { Postu- } \\
\text { lated } \\
\text { error }^{a}\end{array}$ & $\begin{array}{c}T_{1}-1700 \\
K\end{array}$ & $\begin{array}{c}T_{2}-2000 \\
K\end{array}$ & $\begin{array}{c}T_{3}-2300 \\
K\end{array}$ & $\begin{array}{c}\Delta H^{\prime \prime}-73.40 \\
\text { kcal }\end{array}$ & $\begin{array}{c}T_{3}-2300^{b} \\
K\end{array}$ \\
\hline 1 & none & & & & & 0 & 0 & 0 & 0 & 0 \\
\hline 2 & $\mathrm{~h}$ & $\Delta H_{1700}$ of $\mathrm{Au}(\mathrm{l})=\mathrm{Au}(\mathrm{g})$ & kcal & 81.77 & +0.3 & +6.2 & +7.5 & +8.7 & +0.28 & +0.63 \\
\hline 3 & c & $C_{P}$ of $\mathrm{Au}(\mathrm{l})$, all temps. & $\begin{array}{c}\mathrm{cal} \mathrm{mol}^{-1} \\
\mathrm{~K}^{-1}\end{array}$ & 7.953 & +0.15 & +1.3 & +1.9 & +2.8 & +0.18 & +0.41 \\
\hline 4 & $\mathrm{~s}$ & $\mathrm{~S}_{1337}^{\circ}$ of $\mathrm{Au}(\mathrm{l})$ & 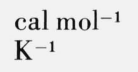 & 23.342 & +0.1 & +3.5 & +4.9 & +6.6 & +0.26 & +0.58 \\
\hline 5 & D & $\Delta H_{0}^{\circ}$ of $\mathrm{Au}_{2}(\mathrm{~g})=2 \mathrm{Au}(\mathrm{g})$ & kcal & 52 & +2.5 & -0.22 & -0.79 & -2.00 & -0.27 & -0.62 \\
\hline 6 & $\omega$ & Fund. freq. of $\mathrm{Au}_{2}(\mathrm{~g})$ & $\mathrm{cm}^{-1}$ & 191 & +10 & +0.01 & +0.05 & +0.14 & +0.03 & +0.06 \\
\hline 7 & $\mathrm{r}$ & $r_{e}$ of $A_{u_{2}}(g)$ & $10^{-8} \mathrm{~cm}$ & 2.68 & +0.2 & -0.03 & -0.12 & -0.38 & -0.07 & -0.16 \\
\hline 8 & $k_{1}$ & $\left(k_{1}^{\prime}+2 k_{1}^{\prime \prime}\right)$ & atm & $(c)$ & $+0.5 \%$ & +0.35 & 0 & 0 & +0.17 & +0.39 \\
\hline 9 & $k_{2}$ & $\left(k_{2}^{\prime}+2 k_{2}^{\prime \prime}\right)$ & atm & $(c)$ & $+0.5 \%$ & 0 & +0.49 & 0 & -0.38 & -0.88 \\
\hline 10 & $k_{3}$ & $\left(k_{3}^{\prime}+2 k_{3}^{\prime \prime}\right)$ & atm & $(c)$ & $+0.2 \%$ & 0 & 0 & +0.26 & +0.11 & +0.26 \\
\hline 11 & $K_{1}$ & $\left(K_{1}^{\prime}+2 K_{1}^{\prime \prime}\right)$ & none & $(c)$ & $+2 \%$ & 0 & 0 & 0 & -1.21 & -2.77 \\
\hline 12 & $K_{2}$ & $\left(K_{2}^{\prime}+2 K_{2}^{\prime \prime}\right)$ & none & $(c)$ & $+0.5 \%$ & 0 & 0 & 0 & +0.95 & +2.18 \\
\hline 13 & $K_{3}$ & $\left(K_{3}^{\prime}+2 K_{3}^{\prime \prime}\right)$ & none & $(c)$ & $+0.2 \%$ & 0 & 0 & 0 & -0.18 & -0.41 \\
\hline 14 & $a$ & See footnote ${ }^{d}$. & cal K ${ }^{-1}$ & 3.6 & +0.5 & 0 & 0 & 0 & +0.39 & +0.90 \\
\hline 15 & $\Delta S^{\prime \prime}$ & See footnote ${ }^{e}$. & cal K -1 & 16.41 & +2 & 0 & 0 & 0 & $f+0.70$ & $f+1.6$ \\
\hline
\end{tabular}

axcept for the percentages, these values are in the units of column 4. ( $1 \mathrm{cal}=4.184 \mathrm{~J}$. $)$

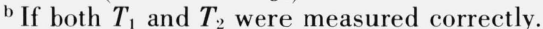

c Those corresponding to the adopted values of the other parameters.

${ }^{\mathrm{d}} a$ and $b$ are constants in the equation $\Delta C_{P}^{\prime}=a+b T$ for the reaction $\mathrm{BeO}(\mathrm{c})+\mathrm{H}_{2} \mathrm{O}(\mathrm{g})=\mathrm{BeO} \cdot \mathrm{H}_{2} \mathrm{O}(\mathrm{g})$.

been estimated [10]. At 1700,2000 , and $2300 \mathrm{~K}$ the former give respectively $2.9,4.0$, and $5.3 \mathrm{~K}$, while the latter give (after interpolating and doubling) $0.3,0.6$, and $0.9 \mathrm{~K}$. For comparison with the above result from table 1 , column 11 , these uncertainty figures may be converted to the same basis by first multiplying by $\partial H^{\prime \prime} / \partial T_{i}$ (table 1 , cases $8-10$ ). The resulting composite temperature error is then calculated to be 1.3 to $9.5 \mathrm{~K}$ for the optical pyrometer, and 0.3 to $1.5 \mathrm{~K}$ for the photoelectric pyrometer, depending on whether the three temperature errors are assumed to have the same or random signs. The corresponding $1.5 \mathrm{~K}$ from the "gold" thermometry thus seems to indicate greater accuracy than optical pyrometry, but poorer accuracy than the best photoelectric pyrometry.

As will be shown in the next section, the simultaneously evaporating gold and beryllium oxide should not be in actual contact with each other, since the water vapor would react extensively with the gold vapor. The foregoing comparison assumes, however, that the two evaporating systems are brought into such good thermal contact that their temperature difference is negligible.
${ }^{\mathrm{e}} \Delta S^{\prime}$, applying to the reaction $2 \mathrm{BeO}(\mathrm{c})+\mathrm{H}_{2} \mathrm{O}(\mathrm{g})=(\mathrm{BeO})_{2} \cdot \mathrm{H}_{2} \mathrm{O}(\mathrm{g})$, was estimated for $2000 \mathrm{~K}$, but the same value is assumed to apply also at 1700 and $2300 \mathrm{~K}$.

${ }^{\mathrm{f}}$ For case No. 15 the actual error in the penultimate column is $+5.3 \mathrm{kcal}$, but the error in $\Delta G_{2300}^{\prime \prime}$ is only $+0.7 \mathrm{kcal}$, to which the tabulated errors would correspond if $\Delta S^{\prime \prime}$ were then corrected to the original value, $16.41 \mathrm{cal} \mathrm{K}^{-1}$.

\subsection{Effects of Contaminants}

The use of the vaporization of gold as suggested in this paper to replace accurate temperature measurement requires that there be no other substance in contact with the gold that would react chemically with an appreciable fraction of the gold vapor species, for the total amount of gold vaporized would otherwise be increased accordingly, and by amounts difficult to correct for reliably. In view of this fact, available and estimated thermodynamic data were used to estimate the extent of such interaction with two candidates for an inert container, graphite and solid beryllium oxide, and with the common gaseous contaminants $\mathrm{O}_{2}, \mathrm{H}_{2}, \mathrm{H}_{2} \mathrm{O}, \mathrm{CO}$, and $\mathrm{CO}_{2}$.

Well-established thermodynamic data were taken from several standard sources $[4,5,11,12]$. In the case of gold-containing molecules whose dissociation energies are uncertain, an attempt was made to adopt upper limits in order to exaggerate the calculated interaction. The dissociation energies (at $0 \mathrm{~K}$ ) of both $\mathrm{AuH}$ and $\mathrm{AuBe}$ were taken as $3.3 \mathrm{eV}$; that of $\mathrm{AuO}$ was taken as $3.5 \mathrm{eV}$ on the basis of a report [13] that at 1200 to $1400{ }^{\circ} \mathrm{C}$ gold is more volatile 
in $\mathrm{H}_{2}$ than in $\mathrm{O}_{2}, \mathrm{~N}_{2}, \mathrm{CO}$, or $\mathrm{CO}_{2}$ at the same pressure; and the dissociation energies of $\mathrm{AuC}$ and $\mathrm{AuOH}$ were roughly estimated as 4.45 and $7.8 \mathrm{eV}$, respectively. Free-energy functions of all the pertinent gold-containing molecules except $\mathrm{AuH}$, whose molecular constants are known [14], were estimated.

The mass fraction of saturated gold vapor reacting with any of these substances (at a given thermodynamic activity) increases with temperature, so for the present example consideration may be limited to the effects at $2300 \mathrm{~K}$. Equilibrium pressures of atomic species and $\mathrm{OH}$ were accounted for, and it was assumed that $\mathrm{BeO}$ produces $\mathrm{AuBe}$ and $\mathrm{AuO}, \mathrm{H}_{2} \mathrm{O}$ produces $\mathrm{AuH}$ and $\mathrm{AuOH}$, and $\mathrm{CO}_{2}$ produces $\mathrm{AuO}$ and $\mathrm{CO}$. The mass fraction of reacting gold vapor at this temperature was found to be 0.3 percent for $\mathrm{BeO}(\mathrm{c})$ and 0.2 percent for graphite (although the latter fraction would be much greater if the dissociation energy of $\mathrm{AuC}$ has been seriously underestimated); thus these two substances appear to be suitable container materials for the gold. The following partial pressures in microns $(1$ micron $\simeq 0.1$ $\mathrm{Nm}^{-2}$ ) each of which would convert 0.3 percent of the gold vapor were calculated to be as follows: $\mathrm{O}_{2}, 2 ; \mathrm{H}_{2}, 3 ; \mathrm{H}_{2} \mathrm{O}, 4 ; \mathrm{CO}_{2}, 2$. (CO is highly inert to gold vapor.) Thus a carrier gas such as argon or nitrogen purified to a rather high degree is indicated to be necessary.

The author is indebted to C. W. Beckett for pointing out the need for carefully estimating the chemical effects of contaminants on the gold vapor.

\section{References}

[1] Grossweiner, L. I., and Seifert, R. L., J. Amer. Chem. Soc. 74, 2701 (1952).

[2] Young, W. A., J. Phys. Chem. 64, 1003 (1960).

[3] Stuart, W. I., and Price, G. H., J. Nucl. Materials 14, 417 (1964).

[4] JANAF Thermochemical Tables, Stull, D. R., and Prophet, H., project directors, 2nd ed., Nat. Stand. Ref. Data Ser., Nat. Bur. Stand. (U.S.), NSRDS-NBS 37, 1141 pages (June 1971).

[5] Hultgren, R., Orr, R. L., Anderson, P. D., and Kelley, K. K., Selected Values of Thermodynamic Properties of Metals and Alloys, (John Wiley and Sons, Inc., New York, 1963), pp. 38-42.

[6] Tester, J. W., Feber, R. C., and Herrick, C. C., J. Chem. Eng. Data 13, 419 (1968).

[7] Schissel, P., J. Chem. Phys. 26, 1276 (1957).

[8] Ackerman, M., Stafford, F. E., and Drowart, J., J. Chem. Phys. 33, 1784 (1960).

[9] Paule, R. C., and Mandel, J., Nat. Bur. Stand. (U.S.), Special Publication 260-19, 21 pages (Jan. 1970).

[10] Lee, R. D., Metrologia 2, 150 (1966).

[11] Stull, D. R., and Sinke, G. C.. The Thermodynamic Properties of the Elements, ACS Monograph Series, Amer. Chem. Soc., W ashington, D.C., 1956.

[12] Gaydon, A. G., Dissociation Energies and Spectra of Diatomic Molecules, 3rd ed., (Chapman and Hall, Ltd., London, 1968).

[13] Mostowitsch, W., and Pletneff, W., J. Russ. Metall. Soc. 1915,410

[14] Herzberg, G., Molecular Spectra and Molecular Structure. I. Spectra of Diatomic Molecules, 2nd ed., (Prentice-Hall, Inc., New York, 1950).

(Paper 76A5-738) 